\title{
A PROSPECTIVE ANALYSIS OF FUNCTIONAL OUTCOME OF USE OF FLEXIBLE NAILS FOR TIBIAL SHAFT FRACTURE IN CHILDREN AND ADOLESCENTS
}

\author{
Yogesh Zadbuke1, Taufiq Panjwani2, Syed Mohsin ${ }^{3}$, Vigneshwaran P4, Prateek Hegde 5 \\ ${ }^{1}$ Associate Professor, Department of Orthopaedics, SBHGMC, Dhule. \\ ${ }^{2}$ Assistant Professor, Department of Orthopaedics, SBHGMC, Dhule. \\ ${ }^{3}$ Senior Registrar, Department of Orthopaedics, L.B.S Hospital, New Delhi. \\ ${ }^{4}$ Senior Registrar, Department of Orthopaedics, Mahatma Gandhi College, Pondicherry. \\ 5Senior Registrar, Department of Orthopaedics, Seth GSMC \& KEMH, Mumbai.
}

\begin{tabular}{l}
\hline ABSTRACT \\
\hline BACKGROUND \\
Tibial and fibular fractures represent the third most common paediatric long bone injuries (15\%) after radial/ulnar and femoral \\
fractures. Controversy persists regarding the best method of treatment between 6 to 16 years with several available options: external \\
fixation, flexible stable intramedullary nails, plate fixation and locked intramedullary nailing.
\end{tabular}

\section{AIMS AND OBJECTIVES}

To study the functional outcome following the use of flexible nails following tibial shaft fractures in children and adolescents.

\section{TYPE OF STUDY}

Prospective interventional study without control group.

\section{MATERIALS AND METHOD}

20 consecutive tibial shaft fractures in children and adolescents presenting to our institute were included over a period of two years. All the patients were treated with flexible intramedullary nails and followed up at 6,12 and 24 weeks. Time to union, complications and functional outcome based on Flynn's criteria was calculated for all patients.

\section{RESULTS}

There was no case of non-union in the study group. Ninety-five percent (19 cases) had excellent functional outcome as per Flynn's criteria. One case had satisfactory outcome and none had poor outcome in the study.

\section{CONCLUSION}

Flexible nailing technique is good, simple, easy, rapid, reliable and effective method for management of tibial fractures between the age of 5 to 16 years.

\section{KEYWORDS}

Tibia Fracture, Flexible Nails.

HOW TO CITE THIS ARTICLE: Zadbuke Y, Panjwani T, Mohsin S, et al. A prospective analysis of functional outcome of use of flexible nails for tibial shaft fracture in children and adolescents. J. Evolution Med. Dent. Sci. 2016;5(32):1755-1758, DOI: $10.14260 /$ jemds/2016/413

\section{INTRODUCTION}

Tibial and fibular fractures represent the third most common paediatric long bone injuries (15\%) after radial/ulnar and femoral fractures.1,2,3 The prevalence of tibial fractures in both boys and girls has increased since $1950.4,3$ If there is not an associated fibula fracture, the intact fibula prevents significant shortening of the tibia; however, varus angulation develops in approximately $60 \%$ of isolated tibial fractures within the first two weeks of injury. ${ }^{3,5}$ A tibial diaphyseal fracture with an associated complete fracture of fibula usually results in valgus malalignment because of the action of muscles in anterolateral aspect of leg. 3

Financial or Other, Competing Interest: None.

Submission 17-03-2016, Peer Review 30-03-2016,

Acceptance 01-04-2016, Published 21-04-2016.

Corresponding Author:

Dr. Yogesh Zadbuke,

Shivpushp Hospital,

Station Road,

Dhule.

E-mail: yzadbuke@gmail.com

DOI: $10.14260 /$ jemds $/ 2016 / 413$
Although long-term studies show that moderate angulation is well tolerated.6,7 the authors recommend that attempts should be made to maintain alignment within 10 degrees of angulation in any direction for children older than 6 years and within 15 degrees of angulation for younger children.1,5,6,7 Rotational deformity may not remodel, although external rotation deformity is better tolerated than internal rotation deformity.1,6 In the last two decades, there was an increased interest in the operative treatment of paediatric fractures, although debate persisted over its indications. There is a little disagreement concerning the treatment of long bone fractures in children less than 6 years (POP cast) and adolescents older than 16 years (Locked intramedullary nailing). ${ }^{8}$ Controversy persists regarding the age between 6 to 16 years with several available options: external fixation, flexible stable intramedullary nails, plate fixation and locked intramedullary nailing.

\section{AIMS AND OBJECTIVES}

1. To study the function outcome following the use of flexible nails for tibial shaft fractures in children and adolescents. 
2. To study the duration of union in the above mentioned fractures.

3. To study the complication of flexible intramedullary nailing of tibial shaft fractures.

\section{Type of Study}

Prospective interventional study without control group.

\section{REVIEW OF LITERATURE}

Over the past 20 years, paediatric orthopaedists have tried a variety of methods to treat paediatric lower limb fractures to avoid prolonged immobilisation and complications. In recent years, use of flexible intramedullary nailing is gaining popularity for unstable tibial fractures in children and adolescents with advantages being minimal soft tissue disturbance with small scar, early mobilization, low infection rate, shorter hospital stay. ${ }^{9}$

Wudbhav N. Sankar et al. between 1998 and 2005 studied 19 consecutive patients between 7.2 and 16 years of age treated with elastic stable intramedullary nailing for unstable tibial shaft fractures. All patients achieved complete healing at a mean of 11.0 weeks (range 6-18 weeks). At final followup, mean angulation was $2^{\circ}\left(\right.$ range $0^{\circ}-6^{\circ}$ ) in the sagittal plane and $3^{\circ}$ in the coronal plane (range $0^{\circ}-9^{\circ}$ ). According to the Flynn classification they had 12 excellent, 6 satisfactory and 1 poor result.

Todd O'Brien, David S. Weisman, Peter Ronchetti et al. over a 5-year period treated 16 unstable tibia fractures in 14 patients with flexible titanium intramedullary nails. The average age was 10 years 4 months. Average time to union was 8 weeks for closed injury and 15 weeks for open injury. There were no malunions. The average follow-up was 1 year 5 months. There were no instances of growth arrest, remanipulations or refracture.

In a systematic review performed by Mark G. Swindells and R. A. Rajan, concluded that elastic intramedullary nailing represents an effective and reliable method to treat an unstable fracture of the tibial diaphysis in the paediatric patient, where conservative management is not appropriate.10,11,12,13 Gamal el-adl, Mohamed F. Mostafa, Mohamed A. Khalil, Ahmed Enan evaluated the results of treatment of 48 paediatric femoral and 25 tibial diaphyseal fractures with Titanium Elastic Nails (TENs); $75.8 \%$ of the results were excellent, $24.2 \%$ were satisfactory and there were no poor results.

The study by Clint W. Johnson, Kelly D. Carmichael, Randal P. Morris and Brian Gilmer compared the biomechanical properties of length of nail fixation past the fracture site in relation to bone diameter. It conlcuded that at 3 diameters or more beyond the fracture site, the length does not significantly affect the biomechanical properties of the construct. Hence, the nails should not be used in proximal or distal long-bone fractures. ${ }^{12}$

\section{MATERIALS AND METHODS}

This is a prospective study, which included all children and adolescent patients between 5-16 years of age with diaphyseal fractures tibia admitted to Chigateri General Hospital and Bapuji Hospital attached to JJM Medical College, Davangere, in the period from September 2010 to September 2012. All closed fractures and Grade I and II compound fractures were included in the study.

\section{Exclusion Criteria Included}

1. Comminuted and segmental fractures of tibia.

2. Compound Grade III injuries.

3. Very distal or proximal metaphyseal fractures that precludes nail insertion.

Patients were operated as early as possible once the general condition of the patient was stable and patient was fit for surgery. After prior informed consent, a pre-operative anaesthetic evaluation was done and pre-op planning of fixation is made. The diameter of the individual nail is selected as per Flynn et al. formula.

Diameter of nail would be calculated as $40 \%$ of the width of the narrowest point of the medullary canal on AP and lateral view. After adequate prepping and draping under anaesthesia, closed reduction and internal fixation with TENS nails done under $\mathrm{C}$-arm guidance.

Post-operatively, patients are immobilized with above knee POP cast for tibia fracture for 6 weeks and such immobilization was continued for another 2-3 weeks based on radiological assessment.

The period of immobilization was followed by active hip, knee and ankle mobilization with non-weight bearing crutch walking. Full weight bearing is started by 8-12 weeks depending on the fracture configuration and callus response. Followup assessment included clinical, radiological assessment and complication at 6,12 and 24 weeks.

Clinical assessment included pain, range of motion evaluation and limb length measurement. Time from surgery to weight bearing was noted. Radiological assessment was done to check alignment and circumferential bridging callus formation on antero-posterior and lateral views.

Complications were classified into minor and major complication. Minor complications were those that did not require additional surgery and did not result in long-term morbidity.

\section{Minor Complications}

1. Pain at the site of nail insertion.

2. Minor angulation $\left(<10^{0}-\right.$ sagittal/coronal; $<10^{0}$ rotational malalignment) at final follow-up (24 weeks).

3. Minor leg length discrepancy $(<2 \quad \mathrm{~cm}-$ shortening/lengthening) at final.

4. Followup (24 weeks).

5. Inflammatory reaction to nails.

6. Superficial infection at site of nail insertion.

7. Delayed union.

Major complications were those that required further operation or there was long-term morbidity associated.

\section{Major Complications}

1. Angulation exceeding the guidelines $\left(>10^{0} \quad-\right.$ sagittal/coronal; or $>10^{0}$ rotational malalignment) at final follow-up.

2. Leg length discrepancy exceeding the guidelines $(>2 \mathrm{~cm}$ - shortening/lengthening) at final followup.

3. Deep infection.

4. Loss of reduction requiring new reduction or surgery.

5. Surgery to revise nail placement.

6. Compartment syndrome requiring surgery.

7. Neurological damage after nailing.

8. Delayed or non-union leading to revision. 
The final outcome based on the above observations is done as per Flynn's criteria.

Flynn's Criteria. TENS outcome score (Flynn et al).2,7

\begin{tabular}{|c|c|c|c|}
\hline $\begin{array}{c}\text { Variables at 24 } \\
\text { weeks }\end{array}$ & Excellent & Satisfactory & Poor \\
\cline { 1 - 2 } $\begin{array}{c}\text { Limb-length } \\
\text { inequality }\end{array}$ & $<1.0 \mathrm{~cm}$ & $<2.0 \mathrm{~cm}$ & $>2.0 \mathrm{~cm}$ \\
\hline Malalignment & 5 degrees & 10 degrees & $\begin{array}{c}>10 \\
\text { degrees }\end{array}$ \\
\hline $\begin{array}{c}\text { Unresolved } \\
\text { pain }\end{array}$ & Absent & Absent & Present \\
\hline $\begin{array}{c}\text { Other } \\
\text { complications }\end{array}$ & None & $\begin{array}{c}\text { Minor and } \\
\text { resolved }\end{array}$ & $\begin{array}{c}\text { Major and } \\
\text { lasting } \\
\text { morbidity }\end{array}$ \\
\hline
\end{tabular}

\section{OBSERVATIONS AND RESULTS}

The study included 20 patients with diaphyseal tibia fracture including 12 males and 8 females. Most cases of fracture were due to road-traffic accident (13 cases). Rest of the cases were due to fall from height ( 5 cases) and sports related injuries (2 cases). Most of the cases were operated within 3 days of injury (15 cases). Only 2 cases took more than 7 days from injury to operation due to preoperative anaesthesia fitness.

Average duration of surgery in our series was 57 minutes ranging from 30-90 minutes. Time to union was calculated for all patients. Sixty percent (12 cases) united by 12 weeks postoperatively. Out of the remaining 8 cases, 7 united by week 15 post-operative. Ninety percent (18 cases) achieved full range of motion at final followup of 24 weeks. Remaining 2 cases had mild restriction of movement. Complications were assessed in all cases till final followup of 24 weeks. It is tabulated in the table as below:

\begin{tabular}{|c|c|}
\hline Complications & No. of Cases \\
\hline Pain & 2 \\
\hline Nail site irritation & 2 \\
\hline Infection & 1 \\
\hline Superficial & 1 \\
\hline Deep & nil \\
\hline Inflammatory reaction & nil \\
\hline Delayed union and non-union & nil \\
\hline Limb lengthening & nil \\
\hline$<2$ cm & 1 \\
\hline$>2$ cm & nil \\
\hline Limb shortening & nil \\
\hline$<2$ cm & 2 \\
\hline$>2$ cm & \\
\hline Nail back out & 2 \\
\hline Malalignment & nil \\
\hline a. Varus angulation & nil \\
\hline b. Valgus angulation & nil \\
\hline c. Anterior angulation & 1 \\
\hline d. Posterior angulation & \\
\hline e. Rotational malalignment & \\
\hline Bursa at the tip of the nail & \\
\hline Sinking of the nail into the medullary \\
cavity
\end{tabular}

According to Flynn's criteria, 95 percent (19 cases) had excellent functional outcome and one case had satisfactory outcome. There was no case with poor outcome in our series.

\section{DISCUSSION}

In the various modalities of treatment available for tibial shaft fractures in children, flexible nailing achieve biomechanical stability from the divergent " $\mathrm{C}$ " configuration, which creates six points of fixation and allows the construct to act as an internal splint.14,15 Titanium nails provide stable and elastic fixation allowing for controlled motion at the fracture site, which results in healing by external callus. ${ }^{15}$ However, only a few limited series have previously discussed the use of titanium elastic nails in tibial shaft fractures. ${ }^{16}$

There are several advantages of this technique. Threepoint fixation within the medullary canal allows maintenance of both alignment and rotation for most fractures. Flexible intramedullary nails provide fixation that is stable as well as elastic allowing micromotion at the fracture site when load is applied. This encourages abundant bridging callus formation and facilitates early union. ${ }^{13,15}$ Because there is no reaming of the medullary canal, the endosteal blood supply is not compromised. The technique allows early weight-bearing in a Sarmiento-type cast or functional brace. ${ }^{17}$ It is important that both nails are of equal diameter, otherwise differential loading of opposite cortices may lead to an angular deformity. There are few articles in the literature on the management of diaphyseal fractures of the tibia in children with intramedullary fixation. 18,19

\section{Time for Union}

In the present study, the mean time for union was found to be 12.6 weeks ranging from 10-16 weeks.

Aksoy C, et al. compared the results of compression plate fixation and flexible intramedullary nail insertion. Average time to union was 7.7 (4 to 10) months in the plating group and 4 (3 to 7) months for flexible intramedullary nailing.

\begin{tabular}{|c|c|}
\hline Studies & $\begin{array}{c}\text { Mean Time of Union } \\
\text { (In weeks) }\end{array}$ \\
\hline Present study & 12.65 \\
\hline Wudbhav N. Sankar et al. & 11 \\
\hline Todd O'Brein et al. & 8 \\
\hline Vallamshetla et al. & 10 \\
\hline Aksoy C, et al. & 16 \\
\hline
\end{tabular}

In our study closed reduction of the fracture, leading to preservation of fracture haematoma, improved biomechanical stability and minimal soft tissue dissection led to rapid union of the fracture compared to compression plate fixation.

The most common complication we came across in our study is irritation at the nail insertion site seen in $2(10 \%)$ of cases which persisted for about 2-3 weeks, later the symptoms subsided without any intervention. As in study conducted by Wudbhav N. Sanker et al. Irritation at the nail entry site was the most common complications following nail insertion, occurring in five patients (26\%). One child required early removal of the nails for this complaint. ${ }^{20}$

Superficial infection was seen in 1 (5\%) case in our study, which was controlled by antibiotics and regular dressing. One case (5\%) developed deep infection which was managed by implant removal, subsequently after serial dressing, and the patient was immobilized by an above knee POP cast for about 16 weeks fracture healed without any deformity. J. M. Flynn et al. reported $4(1.7 \%)$ cases of superficial infection at the site of nail insertion out of 234 fractures treated with titanium elastic nails. ${ }^{15}$ 
We did not find any cases of proximal migration of nail. No cases of delayed union, neurovascular compromise, malunions were seen in our study. We did not find any cases of proximal migration of nail. No cases of delayed union, neurovascular compromise or malunions were seen in our study.

The outcomes according to Flynn's Criteria is compared with the previous studies in Literature in the following table:

\begin{tabular}{|c|c|c|c|}
\hline \multirow{2}{*}{ Studies } & \multicolumn{3}{|c|}{ Outcome } \\
\cline { 2 - 4 } & $\begin{array}{c}\text { Excellent } \\
\text { (\%) }\end{array}$ & $\begin{array}{c}\text { Satisfactory } \\
\text { (\%) }\end{array}$ & $\begin{array}{c}\text { Poor } \\
\text { (\%) }\end{array}$ \\
\hline $\begin{array}{c}\text { Present } \\
\text { Study }\end{array}$ & $\mathbf{9 5}$ & $\mathbf{0 5}$ & - \\
\hline $\begin{array}{c}\text { Gamal El } \\
\text { Adl et al. }\end{array}$ & 75.8 & 24.2 & - \\
\hline $\begin{array}{c}\text { J. M. Flynn } \\
\text { et al. }\end{array}$ & 65 & 25 & 10 \\
\hline $\begin{array}{c}\text { Wudbhav } \\
\text { N. Sankar }\end{array}$ & 63.15 & 31.57 & 5.26 \\
\hline
\end{tabular}

\section{CONCLUSION}

Based on our experience and results, we conclude that flexible nailing technique is good, simple, easy, rapid, reliable and effective method for management of tibial fractures; between the ages of 5 to 16 years, method for treating tibial shaft fractures in children and adolescents.

It is a closed method where the fracture union is achieved by biological means without disrupting the fracture haematoma.

It gives stable fixation in children and adolescents encouraging to early mobilization, shorter hospital stay thereby decreasing the morbidity of the patients. It is an easy, minimally invasive, physeal-protective method.

\section{REFERENCES}

1. Shannak A0. Tibial fracture in children: folloe-up study. J paediatr orthop 1988;8(3):306-10.

2. Rockwood C, Wilkins K, Beaty J, et al. Rockwood and Wilkins' fractures in children. Philadelphia: Lippincott Williams \& Wilkins, 2006;930-43.

3. Karrholm J, Hansson LI, Svensson K. Incidence of tibiofibular shaft and ankle fractures in children. J paediatr orthop 1982;2:386-96.

4. Yang J, Letts M. Isolated fractures of tibia with intact fibula in children: a review of 95 patients. J paediatric orthop 1997;17(3):347-51.
5. Lovell W, Winter R, Morrissy R, et al. Lovell and Winter's paediatric orthopaedics. Philadelphia: Lippincott Williams \& Wilkins, 2006;1504.

6. Hansen B, Grieff J. Fractures of the tibia in children. Acta Orthop Scand 1976;47(4):448-53.

7. Metaizeau JP. Stable elastic nailing for fractures of the femur in children. J Bone Joint Surg Br 2004;86:954-7.

8. Lascombes P, Haumont T, Journeau P. Use and abuse of flexible intramedullary nailing in children and adolescents. J paediatr orthop 2006;26(6):827-34.

9. Mark G Swindells, Rajan RA. Elastic intramedullary nailing in unstable fractures of the paediatric tibial diaphysis: a systematic review. J Child Orthop 2010;4(1):45-51.

10. Setter KJ, Palomino KE. Paediatric tibia fractures: current concepts. Curr Opin Paediatr 2006;18(1):30-5.

11. Huber RI, Keller HW, Huber PM, et al. Flexible intramedullary nailing as fracture treatment in children. J Paediatr Orthop 1996;16(5):602-5.

12. Clint W Johnson, Kelly D Carmichael, Randal P Morris, et al. Biomechanical study of flexible intramedullary nails. J Paediatr Orthop 2009;29(1):44-8.

13. Ligier JN, Metaizeau JP, Prevot J, et al. Elastic stable intramedullary nailing of femoral shaft fractures in children. J Bone Joint Surg Br 1988;70(1):74-7.

14. Ligier JN, Metaizeau JP, Prevot J, et al. Elastic stable intramedullary pinning of long bone fractures in children. Z Kinderchir 1985;40(4):209-12.

15. Flynn JM, Hresko T, Reynolds RA, et al. Titanium elastic nails for paediatric femur fractures-a multicenter study of early results with analysis of complications. J Paediatr Orthop 2001;21(1):4-8.

16. Goodwin RC, Gaynor T, Mahar A, et al. Intramedullary flexible nail fixation of unstable paediatric tibial diaphyseal fractures. J Paediatr Orthop 2005;25(4):5706.

17. Sarmiento A. A functional below-the-knee cast for tibial fractures. J Bone Joint Surg [Am] 1967;49(5):855-75.

18. Qidawi SA. Intramedullary kirschner wiring for tibia fractures in children. J Paediatr Orthop 2001;21(3):2947.

19. Aksoy C, Caolar O, Yazyoy M, et al. Paediatric femoral fractures: a comparison of compression plate fixation and flexible intramedullary nail fixation. J Bone \& Joint Surg (Br) 2003;85-B(Supp III):263.

20. Wudbhav N Sankar, Kristofer J Jones, David Horn B, et al. Titanium elastic nails for paediatric tibial shaft fractures. J Child Orthop 2007;1(5):281-6. 